\title{
EVALUASI PELAKSANAAN KURIKULUM 2013 PADA SMK NEGERI PROGRAM KEAHLIAN TEKNIK BANGUNAN DI DKI JAKARTA
}

\author{
R. Eka Murtinugraba ${ }^{1}$ \\ ${ }^{1}$ Dosen PTB FT UNJ, r ekomn@unj.ac.id
}

\begin{abstract}
Abstrak
Penelitian ini bertujuan untuk mengetahui seberapa besar keterlaksaan kurikulum 2013 terhadap masalah-masalah yang berkaitan dengan pelaksanaan 8 standar nasional pendidikan, di Sekolah Menengah Kejuruan Negeri Program Keahlian Teknik Bangunan di DKI Jakarta yang mencakup: (1) Standar penilaian pendidikan, (2) Standar sarana dan prasarana, (3) Standar pendidik, (4) Tenaga kependidikan, dan (5) Proses pembelajaran.

Penelitian dilakukan pada SMK Negeri di DKI Jakarta yang telah melaksanakan kurikulum 2013, pada tiga sekolah dengan Program Keahlian Teknik Bangunan yang meliputi SMK Negeri 26 Jakarta, SMK Negeri 1 Jakarta, dan SMK Negeri 35 Jakarta. Responden penelitian dalam masing-masing sekolah yaitu 1 kepala sekolah, 1 kepala program keahlian teknik bangunan, dan 6 guru program keahlian teknik bangunan, serta dari peserta didik. Penelitian ini menggunakan metode survei dengan pendekatan kuantitatif.

Hasil penelitian menunjukkan bahwa pelaksanaan kurikulum 2013 di SMK Negeri 26 Jakarta, SMK Negeri 1 Jakarta, dan SMK Negeri 35 Jakarta Program Keahlian Teknik Gambar Bangunan secara keseluruhan, meliputi: (1) Standar penilian pendidikan berada dalam kriteria sangat baik (83\%); (2) Standar pendidik dan tenaga kependidikan dengan memfokuskan pada guru dan kepala sekolah memperoleh nilai rata-rata secara berturut dalam kategori sangat baik (83\%) dan baik sebesar 76\%; (3) Standar sarana dan prasarana berada dalam kriteria sangat baik dengan nilai sebesar 94\% untuk rata-rata ketiga sekolah; (4) Proses kegiatan belajar mengajar di ketiga sekolah tergolong dalam kriteria sangat baik yaitu 80,13\%.
\end{abstract}

Kata Kunci: Evaluasi, Kurikulum 2013, Teknik Bangunan, SMKN Jakarta

\section{EVALUATION OF THE IMPLEMENTATION OF THE 2013 CURRICULUM IN VOCATIONAL SCHOOL PROGRAM SKILL BUILDING ENGINEERING IN DKI JAKARTA}

\author{
R. Eka Murtinugraba ${ }^{1}$ \\ ${ }^{1}$ Leacturer of PTB FT UNJ, rekomn@,unj.ac.id
}

\begin{abstract}
This study aims to find out how much the implementation of curriculum 2013 on issues related to the implementation of the 8 national standards of education, in State Vocational High School Building Engineering Programs in DKI Jakarta which includes: (1) Education assessment standards, (2) and infrastructure, (3) educator standard, (4) education staff, and (5) learning process.

The study was conducted at SMK Negeri in DKI Jakarta which has implemented the 2013 curriculum, in three schools with Building Engineering Expertise Program which includes SMK Negeri 26 Jakarta, SMK Negeri 1 Jakarta, and SMK Negeri 35 Jakarta. Research respondents in each school are 1 principal, 1 head of building engineering skills program, and 6 teachers of building engineering skills program, as well as from learners. This research uses survey method with quantitative approach.
\end{abstract}


The result of the research shows that the implementation of the curriculum of SMK Negeri 26 Jakarta, SMK Negeri 1 Jakarta, and SMK Negeri 35 Jakarta The overall Building Skills Engineering Program includes: (1) Educational evaluation standards are in very good criteria (83\%); (2) The standard of educators and educational personnel by focusing on teachers and principals obtaining the average scores averaging in very good category (83\%) and good by $76 \%$; (3) The standard of facilities and infrastructure is in excellent criteria with a value of $94 \%$ for the average of the three schools; (4) The process of teaching and learning activities in the three schools is classified as very good criteria, namely $80.13 \%$.

Keywords: Evaluation, Curriculum 2013, Building Engineering, SMKN Jakarta

\section{Pendahuluan}

Kurikulum di Indonesia telah berganti beberapa kali, yaitu kurikulum tahun 1947, 1952, 1964, 1968, 1975, 1984, 1994, 2004, 2006, dan 2013. Perubahan kurikulum dimaksudkan untuk mempersiapkan peserta didik agar lebih siap dalam menghadapi tantangan-tantangan di masa depan melalui pengetahuan, keterampilan, sikap dan keahlian untuk beradaptasi serta bisa bertahan hidup dalam lingkungan yang senantiasa berubah. Menurut Mulyasa (2006), Kurikulum adalah seperangkat rencana dan pengaturan mengenai tujuan, kompetensi dasar, materi standar, dan hasil belajar, serta cara yang digunakan sebagai pedoman penyelenggaraan kegiatan pembelajaran untuk mencapai kompetensi dasar dan tujuan pendidikan. Kurikulum juga diartikan menurut Undang-Undang Nomor 20 tahun 2003 sebagai seperangkat rencana dan pengaturan mengenai tujuan, isi, dan bahan pelajaran serta cara yang digunakan sebagai pedoman penyelenggaraan kegiatan pembelajaran untuk mencapai tujuan pendidikan tertentu.

Pendidikan berdasarkan standar menetapkan adanya standar nasional sebagai kualitas minimal warga negara yang dirinci menjadi standar isi, standar proses, standar kompetensi lulusan, standar pendidik dan tenaga kependidikan, standar sarana dan prasarana, standar pengelolaan, standar pembiayaan, dan standar penilaian pendidikan (Permendikbud No.70 Tahun 2013). Satu hal baru terkait dengan Kurikulum 2013 adalah pendekatan saintifik dalam seluruh proses pembelajaran. Pembelajaran saintifik dalam Kurikulum 2013 dikenal adanya kegiatan mengamati, menanya, menalar, mengasosiasi dan mengkomunikasikan (membangun jejaring sosial). Penilaian autentik yang digunakan dalam kurikulum 2013 terdiri atas penilaian sikap spiritual dan sosial, penilaian keterampilan dan penilaian pengetahuan.

SMK Negeri program keahlian Teknik Bangunan di DKI Jakarta yang telah melaksanakan Kurikulum 2013 berjumlah 7 sekolah, yaitu SMK Negeri 1, SMK Negeri 4, SMK Negeri 26, SMK Negeri 35, SMK Negeri 52, SMK Negeri 56 dan SMK Negeri 58.

Pemerintah melalui Peraturan Pemerintah Nomor 19 Tahun 2005 telah menetapkan Standar Pendidikan Nasional (SNP) yang meliputi standar: (1) isi; (2) proses; (3) sarana dan prasarana; (4) pendidik dan tenaga kependidikan; (5) kompetensi lulusan; (6) pembiyaan pendidikan; (7) pengelolaan; dan (8) penilaian pendidikan . Jika ke -8 standar ini terpenuhi maka mutu pendidikan nasional kita akan meningkat dan dapat bersaing dengan mutu pendidikan negara manapun.

Kurikulum 2013 merupakan kurikulum yang memerlukan pengembangan untuk perbaikan di masa yang akan datang. 
Selain itu, juga perlu diketahui hambatan atau kendala yang dihadapi oleh sekolah agar dapat diperbaiki dan memperlancar pelaksanaan Kurikulum 2013 pada tahap selanjutnya yang mengacu pada Standar Nasional Pendidikan (SNP). Pelaksanaannya haruslah dipantau dan dievaluasi untuk mengetahui seberapa jauh kurikulum tersebut telah dilaksanakan agar nantinya hal yang menghalangi kurikulum 2013 ini dapat di atasi dan mengalami kemajuan terutama untuk DKI Jakarta dan daerah lain pada umumnya.

Evaluasi menurut Ralph Tyler dalam Suharsimi Arikunto (2009) adalah sebuah proses pengumpulan data untuk menentukan sejauh mana, dalam hal apa, dan bagian mana tujuan pendidikan tercapai. Tujuan evaluasi adalah untuk memperoleh informasi yang akurat dan objektif tentang suatu program.

Kurikulum 2013 dikembangkan atas dasar teori pendidikan berdasarkan standar (standar-based education), dan teori kurikulum berbasis kompetensi (competency-based curriculum). Rumusan kompetensi inti menggunakan notasi sebagai berikut:

1) Kompetensi Inti-1 (KI-1) untuk kompetensi inti siap spritual.

2) Kompetensi Inti-2 (KI-2) untuk kompetensi inti sikap sosial.

3) Kompetensi Inti-3 (KI-3) untuk kompetensi inti pengetahuan.

4) Kompetensi Inti-4 (KI-4) untuk kompetensi inti keterampilan.

Mata pelajaran SMK tahun 2013 dibagi dalam suatu mata pelajaran kelompok, yang terdiri atas mata pelajaran kelompok A dan mata pelajaran kelompok $B$ yang merupakan kelompok mata pelajaran wajib, serta mata pelajaran kelompok C yang merupakan kelompok mata pelajaran peminatan, terdapat di dalam Permendikbud No.70 Tahun 2013. Tentang standar sarana dan prasarana untuk Sekolah Menengah Kejuruan (SMK)/ Madrasah Aliyah Kejuruan (MAK) tercantum dalam Peraturan Menteri Pendidikan Nasional Republik Indonesia Nomor 40 Tahun 2008.
Standar proses penilaian mencakup, (1) Penilaian, yang meliputi kompetensi pengetahuan, kompetensi keterampilan, dan kompetensi sikap; (2) Konsep penilaian hasil belajar, meliputi kegiatan penilaian, metode dn instrumen penilaian; (3) Prinsip, pendekatan, dan karakteristik penilaian. Untuk standar pendidik dan tenaga pendidik meliputi kualifikasi akademik guru serta standar kompetensi guru (kompetensi pedagogik, kepribadian, sosial, dan professional). Selain itu untuk standar kompetensi kepala sekolah diatur dalam Permen Diknas No.13 Tahun 2007 meliputi (1) Edukator, (2) Manajerial, (3) Administrator, (4) Supervisor, (5) Leader, (6) Inovator, (7) Motivator.

Dalam pasal 1 butir 20 UU Nomor 20 tahun 2003 tentang Sistem Pendidikan Nasional (Sisdiknas), pembelajaran adalah proses interaksi peserta didik dengan pendidik dan sumber belajar pada suatu lingkungan. Standar proses pembelajaran mencakup suatu proses kegiatan, terdiri atas tiga fase atau tahapan. Fase-fase proses pembelajaran yang dimaksud meliputi: tahap perencanaan, tahap pelaksanaan, dan tahap evaluasi atau penilaian hasil pembelajaran.

\section{Metode Penelitian}

Tujuan dari penelitian adalah untuk mendapatkan deskripsi terhadap pelaksanaan Kurikulum 2013 pada SMK Negeri Program Keahlian Teknik Bangunan di DKI Jakarta terutama terkait dengan standar penilaian, standar pendidik dan tenaga kependidikan, dan standar sarana prasarana.

Penelitian dilakukan di tiga SMK Negeri Program Keahlian Teknik Bangunan yaitu SMK Negeri 26 Jakarta, SMK Negeri 1 Jakarta, dan SMK Negeri 35 Jakarta. Subjek dalam penelitian diantaranya kepala sekolah, guru, dan peserta didik.

Penelitian menggunakan metode survei dengan pendekatan kuantitatif. Data kuantitatif merupakan data yang dapat dianalisis secara deskriptif dan berbentuk bilangan. Teknik pengambilan sampel yang 
digunakan adalah Simple random sampling (sampel acak sederhana). Dalam penerapan teknik penarikan sampel acak sederhana, setiap elemen populasi yang sama untuk terpilih menjadi sampel (Dergibson Siagian, 2000).

Teknik pengumpulan dilakukan dengan metode kuisioner atau angket dan dokumentasi. Sebelum angket dijadikan alat pengumpul data, terlebih dahulu digunakan uji instrumen. Uji coba instrumen dilakukan untuk mengetahui kekurangan atau kelemahan dari angket yang telah disusun. Untuk uji validitas pada penelitian ini menggunakan validitas kontruksi dan validitas isi. Untuk mengukur validitas kontruksi, dapat digunakan pendapat para ahli (judgment expert). Dalam hal in setelah instrumen kontruksi tentang aspek-aspek yang akan diukur dengan berdasarkan teori tertentu, maka dikosultasikan dengan ahi (Dosen Pembimbing) dan kemudian divalidasikan kepada dosen ahli yang ditunjuk sebagai validator.

Dan untuk teknik analisis data yang digunakan dalam penelitian ini yaitu analisis deskriptif kuantitatif. Peneliti melakukan pengumpulan data menggunkan kuesioner yang disebarkan kepada responden yang telah dipilih sebagai sampel peniltian. Kuesioner tersebut dikembangkan oleh peneliti menggunakan skala Likert. Kuesioner terdiri dari sejumlah butir pertanyaan atau pernyataan yang dilengkapi oleh 5 alternatif respon atau jawaban. Data ini peneliti ambil untuk mendapatkan data berkaitan dengan standar pendidik dan tenaga pendidikan dan standar proses penilaian. Sedangkan untuk mengumpulkan data berkaitan dengan standar sarana dan prasarana peneliti menggunakan skala Guteman, hanya disediakan dua alternatif jawaban (dikotomi).

\section{Hasil dan Pembahasan}

\section{Deskripsi Data}

Daftar guru dan kepala kompetensi keahlian Teknik Bangunan diketiga sekolah:

Tabel 1. Daftar Jumlah Guru dan Kepala Kompetensi Teknik Bangunan

\begin{tabular}{lcc}
$\begin{array}{l}\text { Nama } \\
\text { Sekolah }\end{array}$ & $\begin{array}{l}\text { Jabatan } \\
\text { Kepala } \\
\text { Kompetensi } \\
\text { Keahlian }\end{array}$ & $\begin{array}{l}\text { Jabatan } \\
\text { Guru }\end{array}$ \\
\hline SMKN 1 & 1 & 4 \\
\hline SMKN 26 & 1 & 9 \\
\hline SMKN 35 & 1 & 6 \\
\hline
\end{tabular}

\section{Analisis Data}

Hasil tes berupa data angka hasil penelitian berdasarkan penilaian responden terhadap objek yang diteliti. Angka tersebut diakumulasikan dalam bentuk persen dan di interprestasikan dalam bentuk kata-kata.

1. Standar Penilaian

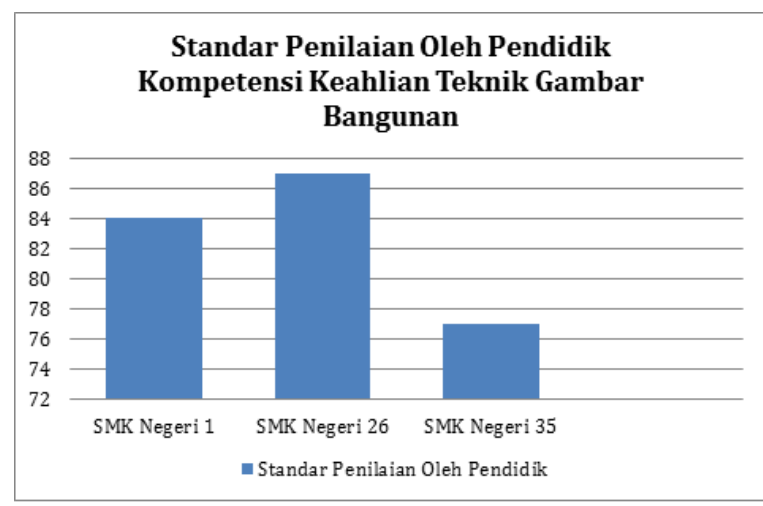

Gambar 1. Diagram Standar Penilian Oleh Pendidik Kompetensi Keahlian Teknik Gambar Bangunan

Gambar 1. Menunjukkan bahwa ratarata pelaksanaan dan pelaporan penilaian oleh pendidik kompetensi keahlian teknik gambar bangunan pada sekolah SMK Negeri 1 Jakarta telah melaksanakan sebesar $84 \%$ (Sangat Baik), pada sekolah SMK Negeri 26 Jakarta telah melaksanakan sebesar $87 \%$ (Sangat Baik), dan pada sekolah SMK Negeri 35 Jakarta telah melaksanakan sebesar $77 \%$ (Baik). Rata- 
rata keseluruhan dari ketiga sekolah SMK Negeri Kompetensi Keahlian Teknik Gambar Bangunan dalam standar penilaian oleh pendidik telah melaksanakan sebesar $83 \%$ (Sangat Baik).

2. Standar Pendidik dan Tenaga Pendidikan

Tabel 2. Rekapitulasi Standar Kompetensi Guru

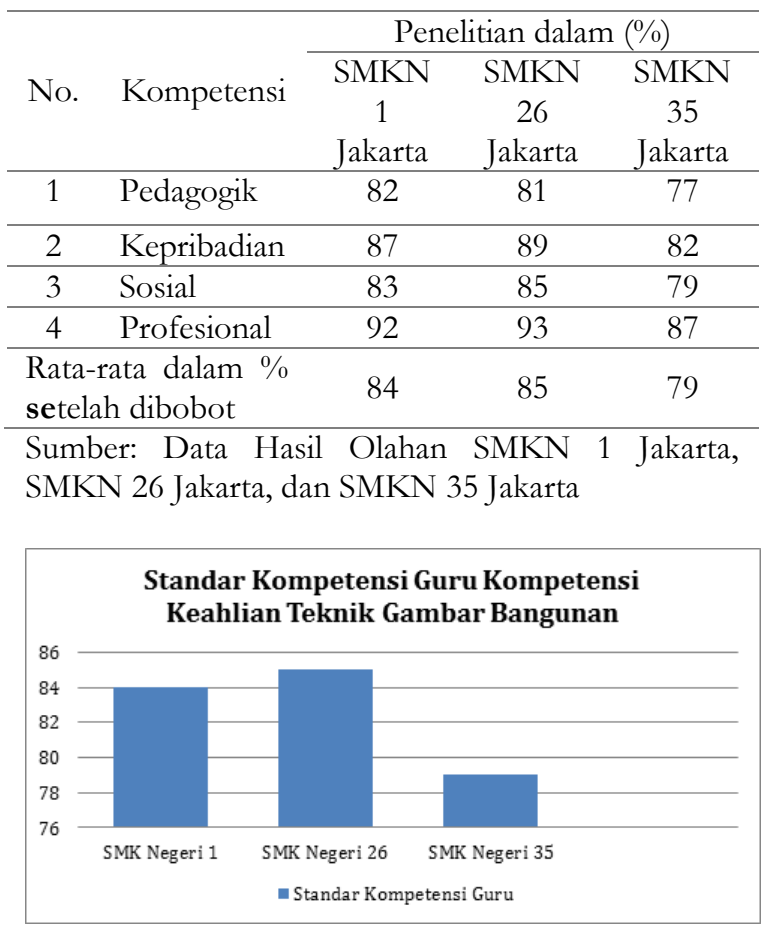

Gambar 2. Diagram Rata-rata Standar Kompetensi Guru Keahlian Teknik Gambar Bangunan

Gambar 2. Menunjukkan bahwa ratarata standar kompetensi guru kompetensi keahlian teknik gambar bangunan pada sekolah SMK Negeri 1 Jakarta mendapat nilai sebesar $84 \%$ (Sangat Baik), pada sekolah SMK Negeri 26 Jakarta mendapat nilai sebesar $85 \%$ (Sangat Baik), dan pada sekolah SMK Negeri 35 Jakarta mendapat nilai sebesar $79 \%$ (Baik). Rata-rata keseluruhan dari ketiga sekolah SMK Negeri Kompetensi Keahlian Teknik Gambar Bangunan pada standar kompetensi guru mendapat nilai sebesar 83 $\%$ (Sangat Baik).
Sementara, untuk data hasil olahan standar kompetensi kepala sekolah sebagai berikut:

Tabel 3. Rekapitulasi Standar Kompetensi Kepala Sekolah

\begin{tabular}{ccccc}
\hline & & \multicolumn{3}{c}{ Penelitian dalam (\%) } \\
\cline { 3 - 5 } No. & Kompetensi & SMKN & SMKN & SMKN \\
& & 1 & 26 & 35 \\
& & Jakarta & Jakarta & Jakarta \\
\hline 1 & Edukator & 63 & 92 & 74 \\
\hline 2 & Manajer & 65 & 91 & 74 \\
\hline 3 & Administrator & 62 & 97 & 72 \\
\hline 4 & Supervisor & 61 & 91 & 74 \\
\hline 5 & Leader & 61 & 97 & 66 \\
\hline 6 & Inovator & 61 & 96 & 72 \\
\hline 7 & Motivator & 61 & 93 & 70 \\
\hline $\begin{array}{l}\text { Rata-rata dalam } \% \\
\text { setelah dibobot }\end{array}$ & 63 & 93 & 73 \\
$\begin{array}{l}\text { Sumber: SMKN 1 Jakarta, SMKN } \\
\text { SMKN 35 Jakarta }\end{array}$ & & \\
\hline
\end{tabular}

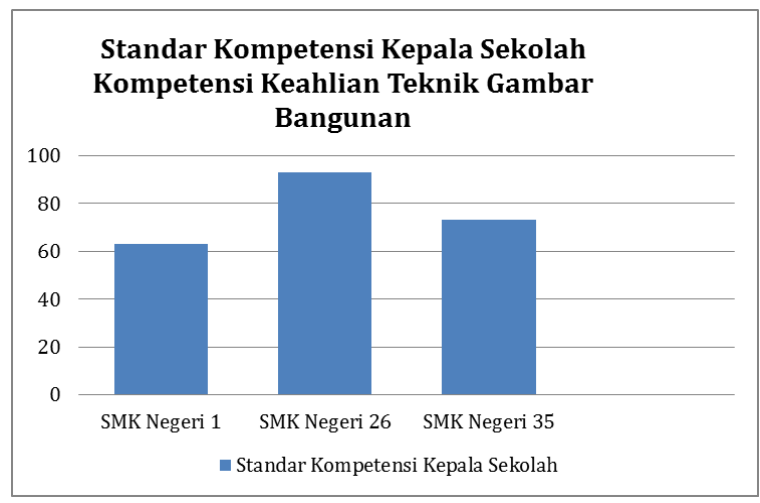

Gambar 3. Diagram Standar

Kompetensi Kepala Sekolah di Nilai dari Responden Kompetensi Keahlian Teknik Gambar Bangunan

Berdasarkan gambar 3. menunjukkan bahwa rata-rata standar kompetensi kepala sekolah dinilai oleh responden keahlian teknik gambar bangunan pada sekolah SMK Negeri 1 Jakarta mendapat nilai sebesar 63 $\%$ (Baik), pada sekolah SMK Negeri 26 Jakarta mendapat nilai sebesar $93 \%$ (Sangat Baik), dan pada sekolah SMK Negeri 35 Jakarta mendapat nilai sebesar $73 \%$ (Baik). Untuk rata-rata keseluruhan dari ketiga sekolah SMK Negeri Kompetensi Keahlian Teknik Gambar Bangunan pada standar kompetensi kepala sekolah mendapat nilai sebesar 76\% (Baik). 


\section{Standar Sarana dan Prasarana}

Sekolah Menengah Kejuruan Negeri Jakarta telah mengacu kepada Standar Nasional Pendidikan, sarana dan prasarana kelengkapan yang dimiliki oleh sekolah tersebut antara lain: 1) Gedung sekolah pondasi permanen dan lokasinya sangat mudah dijangkau, aman dan nyaman, gedung dilengkapi sistem keamanan, dilengkapi fasilitas instalasi listrik dengan daya minimum 1300 watt; 2) Kelengkapan sarana dan prasarana telah dilengkapi dengan adanya ruang kelas, ruang perpustakan, laboratorium, ruang pimpinan (ruang kepala sekolah), ruang guru, ruang tata usaha, tempat beribadah, ruang konseling, jamban (toilet/kamar mandi), gudang, tempat berolahraga, dan ruang praktik kerja/bengkel kerja. Walaupun dari semua item di atas masih ada sekolah yang masih belum memilikinya antara lain laboratorium gambar teknik bangunan, buku siswa, dan buku panduan kurikkulum 2013.

Keterlaksanaan penunjang sarana dan prasarana di dalam Kurikulum 2013 di SMKN 1 Jakarta tercapai sebesar 92\% (Sangat Baik), pada SMKN 26 Jakarta tercapai sebesar $100 \%$, dan pada SMKN 35 Jakarta tercapai sebesar 91\%. Rata-rata keterlakasanaan penunjang Kurikulum 2013 di dalam standar sarana dan prasarana di ketiga sekolah kompetensi keahlian teknik bangunan SMK Negeri di DKI Jakarta sebesar 94\% dalam kriteria Sangat Baik.

\section{Pelaksanaan Pembelajaran}

Pelaksanaan pembelajaran adalah inti dari penyelengaraan pendidikan. Tahap ini merupakan tahap implementasi atau tahap penerapan atas desain perencanaan yang telah dibuat oleh guru. Hakikat dari tahap pelaksanaan pembalajaran adalah kegiatan operasional pembelajaran itu sendiri.

Pelaksanaan proses pembelajaran ada tiga tahapan prosedur yang perlu ditempuh yaitu: pendahuluan, kegiatan inti, dan kegiatan akhir. Kegiatan pendahuluan terdiri, tujuan dari pendahuluan ini agar mengkondisikan para siswa suapaya mereka siap melakukan kegiatan belajar anatara peserta didik dan pendidik harus saling mengenal terlebih dahulu agar menumbuhkan keakraban antara keduanya. Hal yang sangat penting sebelum memasuki kegiatan inti. Ada bererapa langkah yang dilakukan pada kegiatan pendahuluan ini, diantaranya adalah: (1) diawal pertemuan guru memperkenalkan diri kepada peserta didik, (2) peserta didik memperkenalkan diri, (3) siswa menceritakan keadaan mereka, (4) guru melakukan pengabsenan terhadap siswa, (5) guru mengulas garis besar pelajaran sebelumnya jika dibutuhkan, (6) guru memberikan pertanyaan kepada siswa mengenai materi yang akan diberikan, (7) guru menjelaskan mengenai kompetensi dasar yang akan dicapai pada pembelajaran tersebut, (8) siswa diminta mendengarkan guru mengenai cakupan materi dan proses yang akan dilalui pada pembelajaran saat ini.

Kegiatan inti dalam pembelajaran, menggunakan metode yang diseuaikan dengan karakteristik peserta didik dan mata pelajaran. Dan hal tersebut mencakup halhal berikut ini: (1) melakukan observasi atau pengamatan, guru membuka materi secara luas dan bervariasi dan peserta didik melalui kegiatan-kegiatan seperti: melihat, menyimak, mendengar, dan membaca, (2) bertanya, guru membuka kesempatan kepada peserta didik untuk bertanya mengenai apapun yang mereka lihat, mereka simak, atau mereka baca. Penting bagi guru untuk memberikan bimbingan agar peserta didik mengajukan pertanyaan, mengumpulkan dan mengasosiasikan informasi, kegiatan selanjutnya adalah menggali dan mengumpulkan informasi dari beragam sumber dengan berbagai macam cara, (4) mengkonfirmasi hasil, kegiatan terakhir dari kegiatan inti yaitu membuat tulisan atau bercerita tentang apa saja yang telah mereka temukan dalam kegiatan mencari informasi, mengasosiasikan dan menemukan pola. Hasil tersebut disampaikan di depan kelas dan dinilai oleh guru sebgai hasil belajar peserta didik atau kelompok peserta didik tersebut. 
Kegiatan akhir, pada kegiatan penutup guru bersama-sama dengan siswa membuat rangkuman atau kesimpulan pelajaran, melakukan penilaian refleksi terhadap kegiatan yang sudah dilaksanakan secara konsisten dan terprogram, memberikan umpan balik terhadap proses dan hasil pembelajaran, merencanakan tindak lanjut dalam bentuk pembelajaran remidi, program pengayaan, layanan konseling dan memberikan tugas, baik tugas individual maupun kelompok sesuai dengan hasil belajar peserta didi, dan menyampaikan rencana pembelajaran pada pertemuan berikutnya.

Dari hasil penelitian menunjukkan bahwa secara keseluruhan evaluasi terhadap pelaksanaan pembelajaran pada peserta didik kelas X SMKN 1, SMKN 25, dan SMKN 35 Jakarta Kompetensi Keahlian Teknik Gambar Bangunan pada Mata Pelajaran Gambar Teknik tergolong dalam kategori Baik. Rata-rata evaluasi terhadap perencanaan pembelajaran terdapat pada Gambar 4.

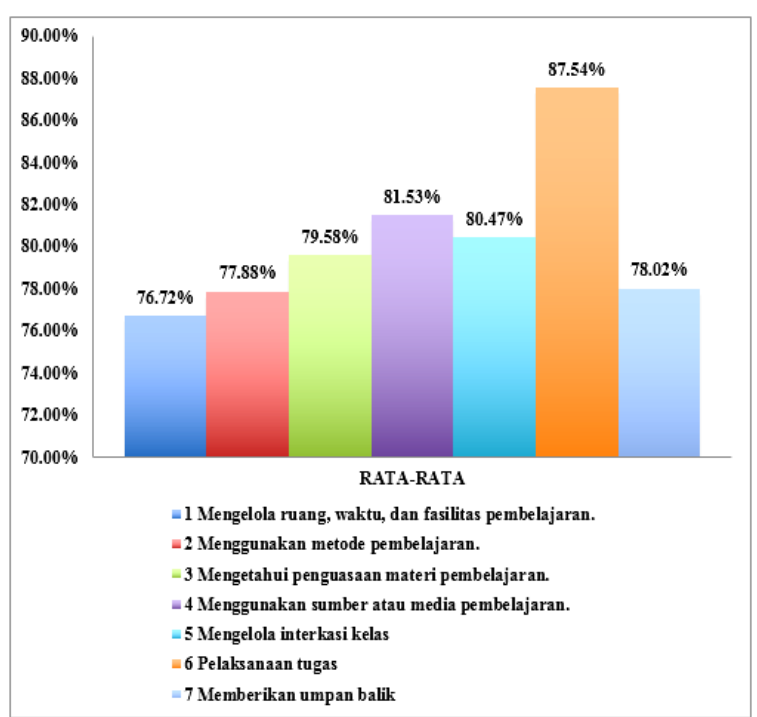

Gambar 4. Rata-rata Pelaksanaan Pembelajaran

Peneliti membahas hasil analisis data berdasarkan jawaban peserta didik di setiap sekolah. Data evaluasi terhadap pelaksanaan pembelajaran yang diperoleh dari jawaban peserta didik SMK Negeri 1, SMK Negeri
26, dan SMK Negeri 35 Jakarta terdapat pada Gambar 5.

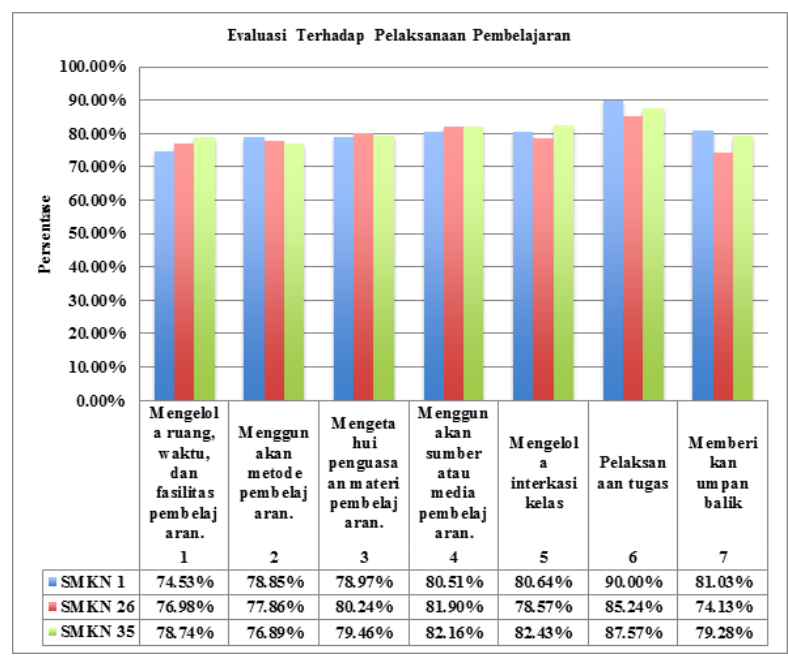

Gambar 5. Penilaian Peserta Didik

Terhadap Evaluasi Pelaksanaan

Pembelajaran

\section{Kesimpulan}

Dari hasil penelitian dan analisa data yang telah dilakukan, maka dapat disimpulkan beberapa hal sebagai berikut:

1. Keterlaksanaan penilaian oleh pendidik kompetensi keahlian teknik gambar bangunan di sekolah SMK Negeri 1 Jakarta, SMK Negeri 26 Jakarta dan SMK Negeri 35 Jakarta sebagai bagian dari standar penilaian. Pendidik telah melaksanakan penilaian kompetensi sikap dalam hal ini observasi, penilaian diri, penilaian antar peserta didik dan jurnal dengan nilai rata-rata dari ketiga sekolah SMK Negeri di DKI Jakarta sebesar 83\% dalam kriteria Sangat Baik.

2. Kemampuan kompetensi guru di dalam Kurikulum 2013 yaitu kompetensi pedagogik, kepribadian, sosial dan profesional beradasarakan penilaian responden di SMKN 1 Jakarta mendapat nilai sebesar 84\% (Sangat Baik), pada SMKN 26 Jakarta mendapat nilai sebesar 85\% (Sangat Baik), dan SMKN 35 Jakarta mendapat nilai sebesar 77\% (Baik). Rata-rata keseluruhan dari ketiga sekolah SMK Negeri Kompetensi Keahlian Teknik Gambar Bangunan di DKI Jakarta pada 
standar kompetensi guru mendapat nilai sebesar $83 \%$ (Sangat Baik).

3. Kemampuan kompetensi kepala sekolah di dalam Kurikulum 2013 yaitu kompetensi edukasi, manajerial, administor, supervisi, leader, inovator dan motivator berdasarkan penilaian responden keahlian teknik gambar bangunan pada ketiga sekolah SMK Negeri di Jakarta mendapat nilai sebesar 76\% (Baik).

4. Keterlaksanaan penunjang sarana dan prasarana di dalam Kurikulum 2013 di SMK Negeri 1 Jakarta tercapai sebesar 92\% (Sangat Baik), pada SMK Negeri 26 Jakarta tercapai sebesar 100\%, dan pada SMK Negeri 35 Jakarta tercapai sebesar 91\%. Rata-rata keterlakasanaan penunjang Kurikulum 2013 di dalam standar sarana dan prasarana di ketiga sekolah kompetensi keahlian teknik bangunan SMK Negeri di DKI Jakarta sebesar 94\% dalam kriteria Sangat Baik.

5. Secara keseluruhan evaluasi terhadap proses kegiatan belajar mengajar di SMK Negeri Jakarta khususnya SMK Negeri 1, 26, dan 35 Jakarta pada Mata Pelajaran Gambar Teknik dilihat dari perencanaan pembelajaran, pelaksanaan pembelajaran dan evaluasi hasil pembelajaran tergolong Sangat Baik dengan rata-rata $80,13 \%$.

\section{Daftar Pustaka}

Arikunto, Suharsimi. (2010). Prosedur Penelitian: Suatu Pendekatan Praktik. Yogyakarta: Rineka Cipta.

Mulyasa, E. (2013). Pengembangan dan Implementasi Kurikulum 2013. Bandung: PT. Remaja Rosdakarya.

Peraturan Menteri Pendidikan dan Kebudayaan.(2013). Peraturan Menteri Pendidikan dan Kebudayaan No.70 Tabun 2013 tentang kerangka dasar dan struktur kurikulum sekolah menengah kejuruan/madrasah aliyah kejuruan. Jakarta: Kementerian Pendidikan dan Kebudayaan.

Peratuaran Menteri Pendidikan Nasional Republik Indonesia Nomor 40 Tahun 2008 tentang standar sarana dan prasarana

Peraturan Pemerintah No. 32 Tahun 2013 tentang Perubahan Atas Peraturan Pemerintah No. 19 Tahun 2005 tentang Standar Nasional Pendidikan.

Undang-Undang Dasar No. 20 Tahun 2003 Pasal 1 Ayat (19) tentang Sistem Pendidikan Nasional. 